\title{
O DESENVOLVIMENTO ECONÔMICO E AS DIVERGÊNCIAS ENTRE O ESTADO E A EMPRESA
}

\author{
ECONOMIC DEVELOPMENT AND DIVERGENCES BETWEEN \\ THE STATE AND THE COMPANY
}

\author{
Alceu Teixeira Rocha* \\ Jussara Suzi Assis Borges Nasser Ferreira**
}

\section{RESUMO}

O artigo propõe-se analisar os preceitos do desenvolvimento econômico. O tema justifica-se, pois na sociedade moderna houve várias mudanças relativas à percepção de desenvolvimento. Objetiva desenvolver uma análise sobre os conceitos históricos de desenvolvimento como sinônimo de crescimento econômico e as divergências entre o Estado e a empresa. O estudo adotou a pesquisa documental e bibliográfica, utilizando doutrinas, artigos e consultas relacionadas à legislação pertinente. Concluindo, entende-se que as mudanças ocorridas em relação à concepção de desenvolvimento, especialmente como liberdade, coadunam-se como um processo social e pluridimensional defendido pela ONU.

Palavras-chave: Desenvolvimento; Econômico; Empresa; Estado; Divergências.

\begin{abstract}
The article proposes to analyze the precepts of economic development. The theme is justified, because in modern society there have been several changes regarding the perception of development. It aims to develop an analysis of the historical concepts of development as synonymous with economic growth and the differences between the State and the company. The study adopted documentary and bibliographic research, using doctrines, articles and consultations related to the pertinent legislation. In conclusion, it is understood that the changes that have occurred in relation to the conception of development, especially as freedom, are consistent as a social and multidimensional process defended by the UN.
\end{abstract}

Keywords: Development; Economic; Company; State; Differences.

\footnotetext{
* Alceu Teixeira Rocha - Doutorando do PPG em Direito - UNIMAR. Professor e Advogado. E-mail: atradvogado@uol.com.br

* Jussara Suzi Assis Borges Nasser Ferreira - Docente Permanente do PPG em Direito - UNIMAR e UNIPAR. Advogada. E-mail: jussara@bflaw.adv.br
} 


\section{INTRODUÇÃO}

O presente artigo busca fazer uma remição do processo de construção da noção de desenvolvimento, identificando suas origens e significados, sua intrínseca relação com a ideia de crescimento econômico, bem como os deslocamentos semânticos ocorridos a partir dos anos 70 do século 20. Nesse período, houve a incorporação de elementos qualitativos à percepção de desenvolvimento, os quais, atualmente, norteiam as discussões em torno do tema, tanto no âmbito das instituições governamentais e organismos multilaterais quanto no da sociedade civil e do debate acadêmico.

Para a obtenção dos resultados almejados pelo trabalho, utilizou-se a pesquisa bibliográfica, abrangendo obras especializadas, revistas, artigos, bem como materiais pertinentes ao tema, com foco no debate central: as divergências entre o estado e a empresa em torno do desenvolvimento econômico.

O artigo possui objetivo de fornecer elementos que possibilitem uma compreensão da gênese e das transformações em torno do conceito de noção de desenvolvimento a partir de ancoragens que levam em conta as formulações institucionais, acadêmicas, econômicas, políticas e sociais. Sendo o principal objetivo de sistematizar historicamente os conceitos de desenvolvimento como sinônimo de crescimento econômico, mostrando as mudanças que levaram ao surgimento da noção de desenvolvimento sustentável, o impacto das políticas do Estado perante as empresas e sociedade e, por fim, abordagem do desenvolvimento como liberdade. O método de abordagem seguido foi o dialético jurídico, abrangendo o fenômeno, fato concreto e a teoria, de forma simultânea, buscando o resultado com o confronto entre os dois.

Também se propõe uma análise contundente do assunto, onde se verifica a discussão do desenvolvimento como sinônimo de crescimento econômico, ideia que, durante grande parte do século 20, orientou políticas governamentais em diversas partes do globo até o surgimento da problemática ambiental nos anos 1960, quando se evidenciou uma crise desse modelo de desenvolvimento e a necessidade de construção de novos padrões de transformação social. A partir da crise observada, constata-se que a temática do desenvolvimento sustentável, busca compreender como essa concepção, substituir o paradigma do desenvolvimento centrado na ideia de crescimento econômico, tornando-se hegemônica nos debates sobre o desenvolvimento e passando a representar a síntese de um acordo político mínimo entre aqueles que defendiam a necessidade de políticas que buscavam o crescimento econômico e aqueles que defendiam a preservação do meio ambiente.

O tema justifica-se pelo fato de que as políticas públicas elaboradas pelo Estado são de suma importância para a sociedade e pretende-se apontar suas possíveis consequências no desenvolvimento econômico do país, com enfoque no crescimento das empresas.

A partir da pesquisa realizada, conclui-se que essas mudanças que ocorrem com relação à concepção de desenvolvimento ao longo da modernidade, em especial a concepção de desenvolvimento como liberdade, se coadunam com a percepção de desenvolvimento, defendida na atualidade pela Organização das Nações Unidas como um processo social e pluridimensional.

\section{DEFINIÇÃO DE DESENVOLVIMENTO ECONÔMICO}

O vocábulo desenvolvimento remete à ideia de transformação, crescimento, progresso; evolução de um status quo antepara uma nova realidade, um estado novo caracterizado por ser

Rev. de Direito, Economia e Desenvolvimento Sustentável | e-ISSN: 2526-0057| Goiânia| v. 5 | n. 1 | p. 39-56| 
qualitativamente, e não apenas quantitativamente, superior ao anterior. Nesse sentido, tal termo se faz presente em diversas áreas do conhecimento humano. Nas ciências sociais, como é o caso da Economia, o termo desenvolvimento encontra-se, em geral, associado ao desenvolvimento humano; o processo no qual a sociedade humana busca melhor realizar as suas virtualidades e potencialidades, Furtado (1981). Nesse sentido, em 1776 lecionava:

Talvez mereça ser observado que a condição dos trabalhadores pobres parece ser a mais feliz e a mais tranquila no estado de progresso, em que a sociedade avança para maior riqueza, e não no estado em que já conseguiu sua plena riqueza. A condição dos trabalhadores é dura na situação estacionária e miserável quando há declínio econômico da nação. O estado de progresso é, na realidade, o estado desejável e favorável para todas as classes sociais, ao passo que a situação estacionária é a inércia, e o estado de declínio é a melancolia (SMITH, 1996, p. 131).

Pondera-se que na busca pela melhor satisfação de suas necessidades, os homens se aglomeram com os seus semelhantes, formando as sociedades. Entretanto, a produção material - criação de bens e serviços (alimentos, vestimentas, alojamentos, entre outros bens) - é vital à própria existência humana. Nas sociedades, tão importante quanto a produção é a distribuição. A forma como a sociedade produz e distribui os bens e serviços que lhe são necessários denomina-se estrutura econômica.

A estrutura econômica é o fundamento sobre o qual se erguem as demais estruturas de uma sociedade, como a política, a cultura, a religião e até mesmo a ciência. Assim, em uma comunidade, a vida social é determinada em última instância pela sua estrutura econômica, Marx (1859). Dessa forma, o desenvolvimento de uma sociedade está intimamente relacionado ao desenvolvimento de sua economia.

O nível de produção de uma sociedade depende, basicamente, do estoque disponível de fatores (capital e trabalho) e da forma como eles são combinados, a qual é definida em razão do padrão tecnológico disponível. Desse modo, o produto de uma sociedade deverá variar somente em caso de alteração no estoque dos fatores, ou se houver alguma mudança tecnológica ocasionadora de uma variação na produtividade destes. Existindo uma elevação sustentada no estoque dos fatores (ex.: uma acumulação sistemática de capital, ou de um crescimento da população economicamente ativa), ou um aumento de produtividade (como seria o caso da incorporação de um avanço tecnológico) deverá ocorrer um aumento no produto social. A produção, tão vital para a sociedade, deverá crescer, tipificando, assim, crescimento econômico. Entretanto, caso esse aumento no produto tenha repercussões nefastas na organização da produção (v.g. seja fruto de um processo de escravização), ou se tal acréscimo for distribuído de maneira fortemente desigual pela sociedade, tal comunidade terá vivenciado um processo de crescimento econômico, mas ela não terá se desenvolvido. Pois, embora o seu produto tenha aumentado, o bem-estar da sociedade não aumentou. Nesse contexto, a busca da sociedade por melhores formas de realização de suas potencialidades e virtualidades foi frustrada, fugindo da tipificação de desenvolvimento, Fauvrelle e Targino (2011). Nesse sentido Amartya Sen: "o crescimento econômico não pode sensatamente ser considerado um fim em si mesmo. $\mathrm{O}$ desenvolvimento tem de estar relacionado sobretudo com a melhoria da vida que levamos e das liberdades que desfrutamos" (2000, p. 29). econômico:

Nesses termos, pode-se apresentar a seguinte definição de desenvolvimento 
O desenvolvimento econômico é o processo de sistemática acumulação de capital e de incorporação do progresso técnico ao trabalho e ao capital que leva ao aumento sustentado da produtividade ou da renda por habitante e, em consequência, dos salários e dos padrões de bem-estar de uma determinada sociedade (BRESSER PEREIRA, 2008, p. 1).

Dessa forma, entende-se desenvolvimento econômico como sendo a evolução de uma sociedade em busca de melhores condições de realizar as suas potencialidade e virtualidades, garantindo, assim, a melhora dos seus padrões de bem-estar.

\section{O DESENVOLVIMENTO ECONÔMICO NA CONSTITUIÇÃO BRASILEIRA}

Embora esteja presente, implicitamente, em praticamente todas as constituições brasileiras, posta a sanha de seu povo por melhores condições de vida, a temática do desenvolvimento apenas foi elevada ao nível constitucional, de forma explícita, a partir da Constituição de 1967. Em seu artigo 157, inciso V, tal texto constitucional prescrevia o desenvolvimento econômico como um dos caminhos para se chegar à justiça social, Tavares (2006). Isso se deve, em parte, aos fatos que aconteciam naquele tempo e à evolução das ideias econômicas.

O fim da segunda guerra mundial marcou o início de uma nova era para as sociedades do globo. Estima-se que naquele tempo cerca de $2 / 3$ da população mundial vivia em condições precárias de existência. Nas décadas seguintes a 1945, a geopolítica mundial passou por grandes transformações. Diversas nações, aproveitando a fragilidade do pós-guerra em suas metrópoles, declararam independência, como foi o caso de diversas nações africanas. O mundo estava dividido entre o bloco socialista, liderado pela URSS, e o capitalista, capitaneado pelos EUA. O grupo socialista vinha mostrando que, através da economia planificada, era possível superar o subdesenvolvimento de alguns países que aderiram ao bloco, Myrdal (1955). De outro lado, a revolução na teoria econômica, promovida por Keynes décadas antes, ao romper com o liberalismo clássico, havia demonstrado a capacidade do estado capitalista de transformar essa realidade.

Nesse cenário de guerra fria e crescente visibilidade das disparidades entre as nações, diversos estudiosos centraram-se na problemática do desenvolvimento econômico. Termos que, aliados aos movimentos políticos da época, fizeram positivar essa temática no corpo constitucional brasileiro. O texto político brasileiro de 1967 fundamenta o regime militar que aqui se implantou. Tal movimento representa a escolha, pelo Brasil, do modelo proposto pelos EUA, qual seja, o do capitalismo de Estado. No mais, seria internalização do artigo primeiro do Pacto internacional relativo aos direitos econômicos, sociais e culturais firmado em 1966, que assim preceituava "Todos os povos têm o direito à autodeterminação. Em virtude deste direito estabelecem livremente a sua condição política e, desse modo, providenciam o seu desenvolvimento econômico, social e cultural" (TAVARES, 2006, p. 134).

Gilberto Bercovici (2005) esclarece que em uma análise meramente quantitativa, descontadas aquelas circunstâncias em que o termo aparece ligado a uma política setorial específica (como educação ou inovação tecnológica), o termo desenvolvimento aparece vinte e oito vezes na Constituição Federal de 1988. Já no preâmbulo da lei fundamental brasileira, o desenvolvimento é posto como um fim ao qual o Estado Democrático deve se dedicar. No corpo principal, a primeira referência do termo desenvolvimento é na qualidade de um dos objetivos fundamentais da República Federativa do Brasil, conforme consta do art. $3^{\circ}$ : 
Art. $3^{\circ}$ Constituem objetivos fundamentais da República Federativa do Brasil: I - construir uma sociedade livre, justa e solidária;

II - garantir o desenvolvimento nacional;

III - erradicar a pobreza e a marginalização e reduzir as desigualdades sociais e regionais;

IV - promover o bem de todos, sem preconceitos de origem, raça, sexo, cor, idade e quaisquer outras formas de discriminação.

Adiante, no inciso IX, art. 21 da Constituição Federal, é previsto como competência da União "elaborar e executar planos nacionais e regionais de ordenação do território e de desenvolvimento econômico e social". Outra referência que vale menção é o $\S 1^{\circ}$, art. 174 também da Constituição Federal. O caput do art. 174 dispõe sobre a competência normativa e reguladora do Estado sobre a atividade econômica, especificando as funções de fiscalização, incentivo e planejamento. Por sua vez, o $\S 1^{\circ}$ prevê a necessidade de uma lei que harmonize os planejamentos nacionais e regionais de desenvolvimento (BERCOVICI, 2005).

Ainda que se trate da lei maior de uma nação, não se pode interpretar uma norma sem a compreensão das políticas que elas visam, nem das teorias que fundamentaram essas políticas, assim como não se pode compreender uma política sem o estudo prévio da lei que a normatiza. Nesse sentido, lei e teoria se entrelaçam de forma que para o melhor estudo de uma, a análise da outra se torna imprescindível. Daí a necessidade de o presente texto passar a analisar as principais correntes econômicas que influenciaram o conceito de desenvolvimento presente na Constituição brasileira (BERCOVICI, 2005).

\section{A TEORIA ECONÔMICA E O DESENVOLVIMENTO}

Conforme Mankiw (1999, p. 4), "Economia é o estudo da forma pela qual a sociedade administra seus recursos escassos. Na maior parte das sociedades os recursos não são alocados por um único planejador central, mas pelas ações combinadas de milhões de famílias e empresas". Embora o estudo da economia tenha muitas facetas, o campo é unificado por várias ideias centrais.

Percebe-se que ao longo da história do capitalismo contemporâneo, intelectuais de várias áreas têm discutido o conceito de desenvolvimento econômico. Entre estes não há uma definição universalmente aceita do conceito de desenvolvimento, mas, para a maioria deles trata-se da relação direta entre desenvolvimento e produção.

Adam Smith, comenta que a riqueza de uma nação se constitui a partir do trabalho produtivo, com aumento dos investimentos em capitais produtivos, a especialização da mãode-obra e a divisão do trabalho. O interesse coletivo é resultado das ações individuais privadas, e os indivíduos buscam atender ao seu interesse próprio, e, ao fazerem isso de forma indireta, acabam por atender aos interesses da coletividade (mão invisível do mercado) (VIEIRA; SANTOS, 2012).

Foi o precursor da moderna Teoria Econômica e postulava que o papel do Estado na economia deveria corresponder apenas à proteção da sociedade contra eventuais ataques e à criação e manutenção de obras e instituições necessárias, mas não à intervenção nas leis de mercado. No estudo da economia, os maiores economistas na época que compreende o século XVIII até o século XX seguiam o método dedutivo em seus estudos, admitindo a intervenção do Estado no terreno econômico (ANDRADE, 2005, p. 24).

Rev. de Direito, Economia e Desenvolvimento Sustentável | e-ISSN: 2526-0057| Goiânia| v. 5 | n. 1 | p. 39-56| 
Entende-se que o termo desenvolvimento econômico é encontrado também na teoria marxista. Marx não se limitou a estudar e entender a realidade histórica, mas criou seu próprio método de trabalho: o materialismo histórico (teoria científica) e o materialismo dialético (filosofia). Para os materialistas, a história da filosofia tem longa tradição idealista, pressuposta até nas teorias em que o idealismo não transparece num primeiro momento, culminando com o pensamento de Hegel, no século XIX. Para esse filósofo, é a própria razão que faz o tecido do real, e a ideia não é uma criação subjetiva do sujeito, mas a própria realidade objetiva, oriundo de toda procedência. Marx explicitou que, embora pretenda-se compreender e definir o homem pela consciência, pela linguagem, pela religião, o que fundamentalmente o caracteriza é a forma pela qual reproduz suas condições de existência.

O materialismo, resultado de múltiplas determinações, não se limita ao determinismo econômico. $\mathrm{O}$ determinante é a própria história, fruto das ações humanas reais. O processo histórico é entendido como o conflito no tempo e no espaço entre unidades contraditórias em contínua transformação, expresso por Marx nos conceitos modo de produção e luta de classes:

Uma crítica leal do marxismo não pode silenciar a parte de verdade que nele se encerra. O marxismo fixou a atenção no aspecto econômico da história, que havia sido muitas vezes olvidado pela historiologia clássica. Acontece, porém, que Marx levado por seu doutrinarismo, exagerou sua importância. Os fatores econômicos influem na história, mas não são os únicos, nem sempre os mais decisivos. Há fatos históricos fundamentais que não podem ser reduzidos à economia (FONTANA, 1969, p. 199).

Para Karl Marx (1996), o capital propicia a produção da mais-valia por meio da exploração do trabalho. O sistema capitalista consiste na produção de mercadorias. Mercadoria é tudo o que é produzido não tendo em vista o valor de uso, mas tem por objetivo o valor de troca, isto é, a venda do produto.

Sendo a mercadoria um produto do trabalho, o seu valor é determinado pelo total de trabalho socialmente necessário para produzi-la. Chama-se mais-valia, portanto, ao valor que o operário cria além do valor de sua força de trabalho, e que é apropriado pelo capitalista (ARANHA; MARTINS, 1993).

A participação do Estado para Furtado (1961) na economia tinha como objetivo melhorar a distribuição regional e setorial dos investimentos, promover melhor distribuição da renda, no sentido de ampliar o mercado consumidor interno, controlar a entrada de capital estrangeiro no país, reduzindo a dependência financeira externa, e oferecer mais autonomia na execução das políticas públicas.

Para Furtado (1967), o aumento do fluxo de renda por unidade de trabalho utilizada é o melhor indicador de desenvolvimento, tal como os clássicos. O desenvolvimento para o autor está ligado ao aumento da produtividade (renda per capita) determinado pelo crescimento econômico com modificações estruturais. O aumento da produtividade do trabalho só é possível com melhor utilização dos recursos, o que implica acumulação de capital, inovação tecnológica e realocação dos recursos que acompanham o aumento do fluxo de renda condicionado pela composição da procura, que é a expressão de valores da sociedade (VIEIRA; SANTOS, 2012).

Desse modo, Furtado condiciona o processo de desenvolvimento econômico ao aumento da produção e da produtividade acompanhado pela melhoria da distribuição da renda, que é importante para aumentar a demanda.

\section{A AÇÃO DO ESTADO NA ECONOMIA}

Rev. de Direito, Economia e Desenvolvimento Sustentável | e-ISSN: 2526-0057| Goiânia | v. 5 | n. 1 | p. 39-56| Jan/Jun. 2019 
Assevera-se que o desenvolvimento econômico, consiste na introdução de novas combinações de fatores de produção que tendem a aumentar a produtividade do trabalho. Este, entretanto, não é fenômeno espontâneo, cujo curso ocorre naturalmente em sistemas capitalistas, mas traduz-se em resultado obtido tão somente da fixação de objetivos políticos e econômicos a serem alcançados em determinado período.

Neste plano, os estados nacionais constituem-se em instrumentos de promoção de desenvolvimento nacional, uma vez dotados de força suficiente para a elaboração e implantação de estratégia nacional, forjando coesão coletiva entre seu governo, empresários, técnicos e trabalhadores para que, empenhados de maneira concertada, possam competir economicamente com as demais nações. A promoção de tais fatores demanda que o Estado Nação, por meio de sua dupla função, seja de instituição normativa e organizacional, tenha influência tal de direcionar as demais intuições e sociedade civil no sentido dos objetivos fixados para alcance do desenvolvimento. Sobre isso disserta Bresser Pereira:

Para que haja desenvolvimento econômico a experiência histórica ensina que é essencial que as instituições garantam, em primeiro lugar, a ordem pública ou a estabilidade política, em segundo lugar, o bom funcionamento do mercado, e, em terceiro lugar, boas oportunidades de lucro que estimulem os empresários a investir e inovar. É necessário, portanto, que o estado, na sua qualidade de instituição maior, seja forte: tenha legitimidade e capacidade para formular políticas, cobrar impostos e impor a lei. Construir estados fortes, capazes de lograr a relativa igualdade necessária à estabilidade política, que, por sua vez, é essencial para o desenvolvimento econômico, é um desafio que as sociedades democráticas modernas enfrentam (BRESSER-PEREIRA, 2006, p. 7).

Salienta-se que a compreensão do papel do estado-nação, entretanto, sofreu profundas transformações ao longo do tempo, à medida que se alteravam aspectos políticos e econômicos. As práticas mercantilistas desenvolvidas na Europa durante a idade moderna, entre os séculos XV e XVIII, pretendiam fortalecer o poder de um Estado em relação aos demais promovendo seu enriquecimento pela atração de capital por meio de uma balança comercial excedentária, subordinada a economia a esse objetivo, sem qualquer observação a aspectos sociais ou liberdades individuais.

Pondera-se que do quase aniquilamento da interferência estatal nos mercados, o capital se viu livre para circulação e investimento, e a defesa da liberdade individual dava origem aos direitos civis, as liberdades políticas e a democracia representativa. Em contrapartida, a ausência de regulação dos mercados tornou desenfreado o ritmo de acumulação, que se concretizou na monopolização do capital por grandes empresas transnacionais, cujas escolhas de entesourar ou investir, ou ainda do consumidor de poupar ou consumir não só não coincidiam com o interesse coletivo, como geravam enormes desigualdades regionais causadas pela concentração de renda e pela divisão internacional do trabalho determinado pelo interesse das grandes potências. A concentração de renda acentuava-se no mesmo nível da produtividade, ao passo que, se questões sociais como marginalização social, violência urbana, dificuldade de acesso à saúde e educação, e pobreza já eram existentes, a essa altura emergiam como verdadeiras chagas nos países de industrialização tardia ou em desenvolvimento.

\section{O ESTADO COMO AGENTE DE DESENVOLVIMENTO ECONÔMICO}

Lourival Vilanova (2003, p. 468-469) aponta que o desenvolvimento é um processo global que mobiliza fatores diversos, quais sejam educacionais, econômico, tecnológico,

Rev. de Direito, Economia e Desenvolvimento Sustentável | e-ISSN: 2526-0057| Goiânia | v. 5 | n. 1 | p. 39-56| 
científico, social, dentro de um quadro planejado com previsão normativa, requerendo planejamento, interligação das variáveis sociais, recursos financeiros e econômicos, investimentos que ultrapassam a capacidade econômica dos particulares, ação racionalizada, direção de processo, e vontade ou decisão de mudança.

O autor acima citado, descreve que o desenvolvimento implica numa decisão de mudança, de haver uma política de desenvolvimento educacional, populacional, econômica, financeira, enfim uma política de investimentos ou de cooperação mundial. Não pode ser senão o Estado, o agente que tem condições de assumir a empresa do desenvolvimento global, integral e racionalizado.

Nota-se que o processo de mudança sociológica que se denomina desenvolvimento seja um processo inter-relacionado de fatores, a ênfase recai sobre o econômico, mesmo que as formas jurídicas não sejam exclusivamente econômicas, direta ou indiretamente sobre elas repercutem. A expressão econômico, na sociedade civil que repousa uma poderosa indústria, montada em grandes capitais e reservas de saber científico e tecnológico, reside na intervenção do Estado na propriedade privada e na ordem econômica.

Salienta-se que na ordem econômica, o Estado reprime o abuso do poder econômico, tabelando preços, impedindo o controle do mercado, por meio de cartéis e trustes.

Ato coeso, Cristiane Derani (2008, p. 223) assinala que a ordem econômica descrita no texto constitucional perfaz a constituição econômica de uma ordem de mercado dirigida globalmente, estando presentes elementos essenciais de uma ordem econômica, dispostos em diretrizes político-econômicas, que são pressupostos de economia de mercado, cuidando da manutenção do equilíbrio global da economia. Havendo desequilíbrio, deve o Estado intervir dentro de um direcionamento global, mesmo que para isso os princípios da livre iniciativa e concorrência acabem sendo relativizados. Os princípios econômicos constitucionalmente positivados encontram-se radicados no pensamento do equilíbrio da atividade econômica de Keynes, que em resumo, visam constituir boas condições econômicas, bem como a reduzir a atuação do Estado como empresário, já que passa a atuar como investidor.

Além disso, Cristiane Derani (2008, p. 225), aponta que a posição de Keynes é criticada pelos monetaristas, que, ao contrário, aconselham uma influência global por meio de uma apropriada política monetária, referindo-se à quantidade em dinheiro. Contudo, o desenvolvimento econômico previsto pela norma constitucional brasileira deve incluir o uso sustentável dos recursos naturais (princípio da defesa do meio ambiente, art. 170, VI; bem como a norma expressa no art. 225, parágrafo $1^{\circ}, \mathrm{IV}$ ), sendo impossível propugnar-se por uma política unicamente monetarista sem colidir com os princípios constitucionais, em especial os que regem a ordem econômica e os que dispõem sobre a defesa do meio ambiente.

Percebe-se que não há como pensar em desenvolvimento da atividade econômica sem o uso racional dos recursos naturais, tendo em vista que a atividade econômica é dependente do fator natureza da produção, na mesma razão da proteção do fator capital e da manutenção do fator de trabalho. A compilação destes três fatores garante a possibilidade de atingir os fins almejados pela ordem econômica constitucional: assegurar a todos existência digna, conforme os ditames da justiça social, previsto no artigo 170 da Carta Magna.

É nessa direção, que o desenvolvimento econômico do Estado brasileiro subentende um aquecimento da atividade econômica dentro de uma política de uso sustentável dos recursos naturais, objetivando um aumento da qualidade de vida coordenada com equilíbrio da distribuição de renda e de condições de vida mais saudáveis, o que não se reduz a um aumento do poder de consumo.

Rev. de Direito, Economia e Desenvolvimento Sustentável | e-ISSN: 2526-0057| Goiânia| v. 5 | n. 1 | p. 39-56| Jan/Jun. 2019 


\section{O IMPACTO DAS POLÍTICAS PÚBLICAS NA SAÚDE DAS EMPRESAS}

A princípio, é necessário esclarecer o real impacto que as políticas públicas desenvolvidas pelo Estado têm na manutenção e no crescimento das empresas. Afinal, não se pode pregar uma posição ativa a quem quer que seja se não lhe forem apresentadas as vantagens da ação e as desvantagens da inércia.

O uso da expressão saúde das empresas é proposital por sua amplitude, já que termos como lucratividade, crescimento efetivo, potencial de crescimento, dentre outros, seriam necessariamente mais restritivos. Na verdade, a comparação da empresa com um organismo vivo - daí a expressão saúde - é bastante apropriada, pois não é saudável um organismo se todas as suas partes não funcionam bem. De modo análogo, é saudável à empresa cujos diversos setores (financeiro, produção, logística, recursos humanos, marketing, entre outros) atuam de forma otimizada e harmônica, atingindo os resultados esperados pela organização. Assim, a aferição da saúde de uma empresa passa por um conjunto heterogêneo de parâmetros, dentre os quais se podem citar, sem pretensão de exaurimento, a lucratividade, o endividamento, o crescimento, o potencial de crescimento, os investimentos realizados, o capital de giro, a produção e o número de contratações e demissões. Consiste, portanto, em uma análise global de toda a organização (PASSOS, 2005).

O primeiro impacto das políticas públicas na saúde das empresas é ex post facto, ou seja, é anterior à sua própria realização. Trata-se, obviamente, da arrecadação de tributos. Se toda política consome recursos, e se o Estado não produz riquezas, será a arrecadação compulsória de tributos que permitirá a realização das medidas estatais. Dessa forma, o fato de as empresas serem financiadoras (ainda que compulsoriamente) das políticas públicas realizadas pelo Estado já seria motivo para fiscalizarem, controlarem e influenciarem essas iniciativas. Se o dinheiro lhes será tomado de qualquer forma, elas podem, ao menos, garantir que ele tenha uma destinação correta. Posteriormente, no momento em que os recursos arrecadados serão gastos, ocorrerá o segundo impacto, e o efeito sobre as empresas pode ser bem maior. Tratando das funções econômicas do setor público, Passos afirma que:

1.1 Fornecer Infraestrutura Institucional

Cabe ao setor público fornecer parte da infraestrutura física (rodovias, aeroportos, pontes e demais bens assemelhados), bem como a infraestrutura institucional do sistema de mercado, tais como leis, tribunais e órgãos reguladores. A existência de um sistema legal garante os direitos de propriedade privada e permite o estabelecimento e o cumprimento de contratos. Os Órgãos Reguladores, por sua vez, podem arbitrar relações econômicas, punir crimes e impor penalidades apropriadas (PASSOS, 2005, p. 438).

Percebe-se, pois, a essencialidade do papel do governo no desenvolvimento econômico das organizações. Como poderia uma empresa crescer se não houvesse estradas para escoar a produção, portos para exportar ou leis que protegessem seus contratos?

No ambiente macroeconômico, o governo pode adotar uma política fiscal expansionista (diminuir tributação e/ou aumentar seus gastos para fomentar a produção) ou restritiva (aumentar a tributação e/ou diminuir seus gastos para conter a produção). Tal decisão caberá a economistas ligados ao Estado e será baseada em fatores como inflação e crescimento econômico. Essa escolha terá impacto fundamental no planejamento e elaboração de políticas públicas, pois, se elas consomem necessariamente recursos, a propensão do governo de gastar mais ou menos influenciará em seu desenvolvimento (PASSOS, 2005). 
O autor explana que se for efetiva a política fiscal expansionista é a melhor para o crescimento imediato das empresas, é com uma política restritiva que o administrador deve mostrar todo o seu potencial. Afinal, sua competência pode ser medida comparando-se os resultados alcançados com os recursos disponíveis. Quanto mais escassos os recursos à disposição e melhor o resultado alcançado, mais competente será o administrador.

Assevera-se que independentemente da decisão governamental de gastar mais ou menos, as políticas públicas que serão realizadas devem ter um objetivo claro e idôneo, e sua implementação deve ser a mais eficiente possível. Se, por exemplo, far-se-á determinado programa de distribuição de renda, deve-se avaliar se os meios utilizados visam a, efetivamente, reduzir a pobreza a longo prazo ou se somente têm intuitos eleitoreiros e demagógicos. $\mathrm{Na}$ primeira hipótese, a política trará desenvolvimento econômico para o país e, consequentemente, para as empresas. Na segunda, criará um sumidouro de dinheiro público, uma situação de perpetuação do assistencialismo e da miséria e, consequentemente pobreza e ineficiência crônicas.

Portanto, percebe-se que as mais diversas políticas públicas podem ter um efeito, mesmo que indireto, na saúde e no crescimento das empresas.

Estima-se em que se permite que os políticos ajam livremente, sem o controle da população, farão o que lhes for mais conveniente (que dificilmente coincide com os interesses do povo). Haverá, então, corrupção, desperdício de dinheiro público, políticas públicas inócuas, demagógicas e eleitoreiras. Por outro lado, se os políticos forem vigiados, controlados e pressionados, tenderão a utilizar melhor o dinheiro arrecadado com impostos, trazendo melhores resultados para as empresas e para a população como um todo.

\section{A SUSTENTABILIDADE COMO PERCEPÇÃO DE DESENVOLVIMENTO}

A noção de desenvolvimento sustentável emerge com a compreensão/percepção da finitude dos recursos naturais e da inviabilidade do modelo de desenvolvimento vigente na maioria dos países. Tal modelo tinha como pressuposto a industrialização, o crescimento econômico e o avanço da ciência, conforme discutido no item anterior (SILVA; NELSON; RAMOS SILVA, 2018, p. 51). A crise desse modelo, em que desenvolvimento e crescimento econômico aparecem como sinônimos, inicia-se com os questionamentos em relação à capacidade de autorregulação da natureza e da inesgotabilidade dos recursos naturais, provocados, dentre outros fatores, pela crise mundial do petróleo em 1973 e pelo surgimento do movimento ambientalista, os quais foram fundamentais para alertar o mundo de que os recursos naturais não são inesgotáveis. Conforme Amazonas e Nobre (2002):

No final dos anos 1960 e 1970, a emergência do movimento ambientalista e o choque do petróleo fizeram da energia, dos recursos naturais e do ambiente em geral um tema de importância econômica, social e política, eclodindo o debate da questão ambiental, AMAZONAS; NOBRE, (2002, p. 193).

Particularmente, a crise do petróleo e a necessidade do seu racionamento nos países ricos alertaram a população para a finitude dos recursos naturais e, consequentemente, para a necessidade do uso racional e planejado. Tais questões reeditam em parte as discussões propostas por Thomas Malthus quando da formulação da Teoria dos Limites, em 1798 (SILVA; NELSON; RAMOS SILVA, 2018, p. 51).

Na segunda metade do século 20 as discussões sobre o desenvolvimento avançam e se intensificam mais ainda com a publicação do relatório do Clube de Roma, em 1972, resgatando, ainda que em outro contexto, as ideias de Malthus. O referido documento, intitulado The limits

Rev. de Direito, Economia e Desenvolvimento Sustentável | e-ISSN: 2526-0057| Goiânia| v. 5 | n. 1 | p. 39-56| 
to the growth, abalou a crença de que a industrialização ou padrão tecnológico das economias avançadas era o caminho do desenvolvimento ao anunciar o esgotamento próximo das principais reservas de minérios, a explosão demográfica nas décadas seguintes e o aumento exponencial da poluição e degradação dos ecossistemas naturais, os quais implicariam diminuição da qualidade de vida, principalmente entre os países industrializados (DIEGUES, 1992).

O documento produzido relacionava a quatro grandes questões consideradas relevantes para a sustentabilidade no planeta: o controle do crescimento populacional, a insuficiência da produção de alimentos, o controle do crescimento industrial e o esgotamento dos recursos naturais (SILVA; NELSON; RAMOS SILVA, 2018, p. 52).

Ainda, segundo as autoras, no que se refere à necessidade do controle do crescimento populacional, o relatório propunha uma política de restrição à natalidade, reeditando uma antiga proposta de Malthus. O problema da insuficiência da produção de alimentos era visto como um dos principais, uma vez que os objetivos de aumentar o bem-estar da sociedade, incluindo as tecnologias agrícolas voltadas para o aumento da produtividade das culturas, manifestaram efeitos indesejáveis. No que diz respeito ao controle do crescimento industrial e ao esgotamento dos recursos naturais, Sachs (2001) alerta para a necessidade de um compromisso por parte dos governos no sentido de comprometer-se com o novo padrão de desenvolvimento.

Os debates em torno dessas questões prosseguiram durante toda a década de 70 , contribuindo para a emergência de novas propostas que buscavam combinar crescimento econômico e defesa do meio ambiente. Na conferência de Estocolmo, em 1972, surge o conceito de eco desenvolvimento. Lançado inicialmente por Maurice Strong, o novo termo foi definido como:

[...] um estilo de desenvolvimento adaptado às áreas rurais do Terceiro Mundo, baseado na utilização criteriosa dos recursos locais, sem comprometer o esgotamento da natureza, pois nestes locais ainda havia a possibilidade de tais sociedades não se engajarem na ilusão do crescimento mimético (LAYRARGUES, 1997, p. 4).

Do mesmo modo, foi na década de 80 que o economista Ignacy Sachs (2009) se apropria do termo e o desenvolve conceitualmente, criando um quadro de estratégias ao eco desenvolvimento. As premissas desse modelo baseiam-se em três pilares: eficiência econômica, justiça social e prudência ecológica.

Além das questões ambientais e sociais, à proposta desenvolvida por Sachs (2001) são agregadas a gestão participativa, a ética e a cultura. Nas discussões sobre o tema, o autor delineia seis aspectos que deveriam guiar o desenvolvimento: a) satisfação das necessidades básicas; b) solidariedade com as gerações futuras; c) participação da população envolvida; d) preservação dos recursos naturais; e) elaboração de um sistema social garantindo emprego, segurança social e respeito a outras culturas e; f) programas de educação.

No que se refere à satisfação das necessidades básicas, o eco desenvolvimento propõe um comprometimento com a prudência ecológica e a justiça social, ao mesmo tempo em que sugere a definição de um teto do consumo material que limita o mercado e diminui o consumo de supérfluos. Referente à solidariedade com as gerações futuras, o conceito de eco desenvolvimento propõe um comprometimento com o futuro que condicionaria as escolhas do presente. Para Sachs (2001), trata-se de um princípio ético básico.

Quanto à participação da população envolvida, o autor destaca a necessidade de um amplo conhecimento das culturas e dos ecossistemas, sobretudo da forma de relacionamento

Rev. de Direito, Economia e Desenvolvimento Sustentável | e-ISSN: 2526-0057| Goiânia| v. 5 | n. 1 | p. 39-56| Jan/Jun. 2019 
das pessoas com o ambiente e as estratégias adotadas para enfrentar os dilemas cotidianos, além do envolvimento dos cidadãos no planejamento das políticas, considerando que são os maiores conhecedores da realidade local.

Na discussão sobre a preservação dos recursos naturais, destaca-se a necessidade de uma relação simbiótica entre homem e natureza, de modo a garantir a produção de tecnologias que mais bem se adaptem às condições naturais e culturais de cada ecorregião do mundo, satisfazendo, assim, as necessidades culturais humanas e, ao mesmo tempo, respeitando os limites naturais de cada ambiente (SILVA; NELSON; RAMOS SILVA, 2018, p. 53).

Quanto à elaboração de um sistema social, garantindo emprego, segurança social e respeito a outras culturas, bem como aos programas de educação, o autor atribui um papel central ao Estado, uma vez que esses itens são basilares para a efetivação do eco desenvolvimento e dificilmente seriam atendidos pelo mercado.

De acordo com Sachs (2009), para promover o eco desenvolvimento as ações deveriam essencialmente:

(...) ajudar as populações envolvidas a se organizar a se educar, para que elas repensem seus problemas, identifiquem as suas necessidades e os recursos potenciais para conceber e realizar um futuro digno de ser vivido, conforme os postulados de Justiça social e prudência ecológica (SACHS, 2009, p. 32).

Conforme Godoy e Pamplona (2007), essas contribuições ao conceito de desenvolvimento acrescentam-lhe uma face qualitativa e intergeracional. Com isso, a concepção de desenvolvimento passou a incluir tanto as questões econômicas quanto as preocupações com seus impactos sociais e ambientais para a população de hoje e para as futuras gerações.

Em 1987, com o lançamento do Relatório Brundtland pela Comissão Mundial sobre o Meio Ambiente e Desenvolvimento da ONU, aprofunda-se a discussão em torno da ideia de um desenvolvimento para além da dimensão econômica. Essa ideia passou, então, a ser amplamente debatida enquanto uma tentativa de equacionar o problema entre crescimento e preservação ambiental. De acordo com Campos (2009), foi na Conferência das Nações Unidas sobre Ambiente e Desenvolvimento Sustentável, no Rio de Janeiro, em 2002, que essas concepções, aparentemente inconciliáveis, encontram no conceito de desenvolvimento sustentável uma estratégia de aproximação e conciliação, passando a representar a síntese de um acordo político entre aqueles que defendiam a necessidade de políticas que buscavam o crescimento econômico e aqueles que defendiam a preservação do meio ambiente.

A noção de sustentabilidade acrescenta à perspectiva de desenvolvimento outras dimensões que vão além da econômica. Questões como equidade, preservação e conservação do meio ambiente, justiça social, entre outras, passam a compor as discussões a respeito do desenvolvimento que agora é adjetivado como sustentável, isso porque:

[...] além de promover um acordo entre ambientalistas e desenvolvimentistas, a ideia de desenvolvimento sustentável também provocou um processo de complexificação acerca do debate sobre desenvolvimento, em que se vislumbram diversas formulações teóricas que se esforçam em tentar ampliar a ideia inicialmente difundida pela Conferência Mundial de Meio Ambiente (CAMPOS, 2009, p. 25).

O novo termo se define como um processo de mudança no qual a exploração dos recursos, a orientação para os investimentos, os rumos do desenvolvimento tecnológico e a mudança institucional estão de acordo com as necessidades atuais e futuras. A nova estratégia 
compatibiliza, no tempo e no espaço, "o crescimento e a eficiência econômica, a conservação ambiental, a qualidade de vida e a equidade social", assumindo um compromisso com as próximas gerações (ONU, 1987).

A expressão desenvolvimento sustentável, para Herculano (1992), possui uma elasticidade semântica que lhe permite abrigar desde um sentido radical, voltado para um novo modelo de sociedade, até um significado conservador, no qual o desenvolvimento capitalista assume uma preocupação social e ambiental. Corroborando essas ideias, Castro (1996) afirma que duas razões fortaleceram a definição do desenvolvimento sustentável proposta pelo Relatório Brundtland. A primeira é que, por ser uma expressão axiologicamente neutra, pode ser incorporada por diversos grupos com interesses e orientações políticas distintas. A segunda é que, por exprimir uma economia maior com o funcionamento dos ecossistemas naturais, tornou-se atrativa também aos ambientalistas.

Não obstante tais constatações, o mérito da noção de desenvolvimento sustentável foi à institucionalização da problemática ambiental, produzindo uma elevação dos debates sobre o tema ao primeiro plano da agenda política internacional, com repercussão no âmbito dos governos e da sociedade civil.

Certamente esse é um debate ainda em construção na medida em que não existe um consenso acerca do termo. Tal fato abre espaço para a incorporação de novos termos no debate, seja negando aspectos até então considerados consensuais, seja ampliando a construção realizada até o momento, com base na inserção de novos elementos, tal como proposto na formulação de Amartya Sen (2000).

\section{A PERSPECTIVA DO DESENVOLVIMENTO COMO LIBERDADE}

Nas inúmeras discussões sobre o tema, estabeleceu-se uma verdadeira polissemia em torno do seu significado. Várias motivações foram criadas e recriadas para justificá-lo e diferentes mecanismos acionados na busca de trilhar os seus caminhos. Nessa perspectiva, surgem diversas proposições que se empenham para recolocar a sociedade como razão primordial do desenvolvimento, incorporando o meio ambiente como uma dimensão desse processo. Nesse cenário de inovações teórico-metodológicas, destacam-se: a abordagem das necessidades básicas, que tem procurado incorporar variáveis qualitativas nas análises econômicas; e, as concepções de Amartya Sen (2000), economista indiano que desenvolveu a abordagem das capacitações, que compreende o desenvolvimento como um processo de ampliação das liberdades.

A perspectiva do desenvolvimento como liberdade parte da constatação de que o mundo contemporâneo atingiu um alto grau de opulência ao mesmo tempo em que ainda convive com antigos problemas, tais como: a persistência da pobreza, a violação das liberdades políticas, a fome, entre outros aspectos relevantes, Sen (2000). Superar esses problemas, assim, é um aspecto central do processo de desenvolvimento, que passa a ser avaliado a partir da sua capacidade de eliminar as diversas privações vivenciadas pelos indivíduos. A ideia de privação é vista pelo autor como restrições que impossibilitam as pessoas de realizarem suas escolhas.

As privações, segundo a concepção seniana, podem ser identificadas na constância da pobreza, na não satisfação de necessidades essenciais, na ausência de liberdades políticas e civis, dentre outras formas. Tais situações podem ser encontradas tanto nos países ricos quanto em países pobres. Ao tratar sobre as diversas formas de privação, Sen destaca como fundamental a liberdade de opinar e decidir, pois:

Há um número enorme de pessoas em diversos países do mundo às quais são sistematicamente negadas a liberdade política e os direitos civis básicos [...].

Rev. de Direito, Economia e Desenvolvimento Sustentável | e-ISSN: 2526-0057| Goiânia| v. 5 | n. 1 | p. 39-56| 
Porém - mais fundamentalmente -, a liberdade política e as liberdades civis são importantes por si mesmas, de um modo direto; não é necessário justificálas indiretamente com base em seus efeitos sobre a economia (SEN, 2000, p. 29).

As diversas discussões em torno do desenvolvimento têm provocado uma ampliação do debate sobre modelos, provocando um deslocamento que aponta para a construção de alternativas econômicas sustentáveis e para a ideia de um desenvolvimento humano, em que:

Uma concepção adequada de desenvolvimento deve ir muito além da acumulação de riqueza e do crescimento do Produto Nacional Bruto e de outras variáveis relacionadas à renda. Sem desconsiderar a importância do crescimento econômico, precisamos enxergar além dele (SEN, 2000, p. 28).

Ainda segundo o autor, somente há desenvolvimento quando os benefícios do crescimento servem à ampliação das capacidades humanas, entendidas como o conjunto das coisas que as pessoas podem ser ou fazer na vida. Para o autor, existem quatro capacidades humanas consideradas elementares: a) ter uma vida longa e saudável; b) ser instruído; c) ter acesso aos recursos necessários a um nível de vida digno e; d) ser capaz de participar da vida em comunidade. Na ausência dessas quatro capacidades, todas as outras estão indisponíveis, tornando inacessíveis muitas oportunidades na vida das pessoas. É importante destacar a articulação estabelecida entre as capacidades elencadas pelo autor, na medida em que uma capacidade pode contribuir para a ampliação da outra. Tais capacidades podem também ser ampliadas pela política pública ao mesmo tempo em que a política pode ser influenciada pela capacidade de participação do povo. Existe, então, uma importância de as pessoas serem livres para que suas escolhas e decisões que afetarão sua vida possam ser exercidas.

Nessa nova forma de conceber o desenvolvimento, a condição de agente dos indivíduos é central para lidar com os problemas e privações diversas a que estão submetidos. Destaca-se, entretanto, que a condição de agente é limitada pelas oportunidades sociais, políticas e econômicas de que o indivíduo dispõe. Segundo Porsse, o termo agente, adotado por Sem (2000), significa que:

(...) é usado em uma acepção relacionada a indivíduos que agem e ocasionam mudanças, sendo suas realizações julgadas em termos de seus próprios objetivos e valores. Enquanto agentes ativos de mudança, as pessoas podem cuidar de si mesmas, influenciar o mundo e ajudar uns aos outros. Conforme o aspecto de agência, os indivíduos não são vistos como meros beneficiários passivos de programas de desenvolvimento, mas sim como membros de uma sociedade que participam de ações políticas, econômicas e sociais, bem como interagem no mercado, na esfera política e em outras esferas (PORSSE et al., 2008, p. 142).

Discutindo a ideia de agente, Sen (2000) chama a atenção para o fato de o termo tratar de alguém que age e ocasiona mudanças e cujas realizações podem ser julgadas de acordo com seus próprios objetivos e valores. Assim, a condição de agente de uma pessoa é refletida pela sua liberdade; então, quanto mais liberdade, maior o potencial e a condição para realizar mudanças e influenciar processos nas diversas esferas da vida social, seja econômica política ou social.

As oportunidades econômicas, liberdades políticas, poderes sociais, bem como as condições habilitadoras (saúde, educação básica, incentivo e aperfeiçoamento de iniciativas),

Rev. de Direito, Economia e Desenvolvimento Sustentável | e-ISSN: 2526-0057| Goiânia| v. 5 | n. 1 | p. 39-56| 
por sua vez, influenciam sobremaneira o que as pessoas conseguem positivamente realizar. As disposições institucionais que proporcionam essas oportunidades são ainda influenciadas pelo exercício das liberdades das pessoas, mediante a liberdade para participar da escolha social e das tomadas de decisão públicas que impelem o progresso dessas oportunidades (SEN, 2000).

A noção de liberdade não deverá ser considerada uma condição do sujeito tomado isoladamente. Nessa acepção, liberdade não é necessariamente liberalismo econômico ou desregulamentação da vida social; pelo contrário. O autor defende a ampliação das oportunidades sociais, que em alguns casos deverá ser mediada pelo Estado. Destarte, a ideia de liberdade proposta por Sen (2000) coaduna-se com o pensamento de Barroco (2001, p. 42), quando afirma que "a liberdade é, ao mesmo tempo, capacidade de escolha consciente dirigida a uma finalidade, e, capacidade prática de criar condições para a realização objetiva das escolhas, para que novas escolhas sejam criadas".

De acordo com essa abordagem, a expansão da liberdade é considerada o fim primordial e o principal meio do desenvolvimento. Assim, a liberdade assume um papel constitutivo e um papel instrumental na construção do desenvolvimento, em que:

$\mathrm{O}$ papel constitutivo relaciona-se à importância da liberdade substantiva no enriquecimento da vida humana. As liberdades substantivas incluem capacidades elementares como, por exemplo, ter condições de evitar privações como a fome, a subnutrição, a morbidez evitável, e morte prematura, bem como as liberdades associadas a saber ler e fazer cálculos aritméticos, ter participação política e liberdade de expressão (SEN, 2000, p. 52).

A expansão da liberdade, assim, é vista como o principal fim e o principal meio do desenvolvimento, o qual passa a ser concebido como um processo de expansão das liberdades reais que as pessoas desfrutam. A liberdade, nessa compreensão, é um elemento central no processo de desenvolvimento em virtude de duas razões: a razão avaliatória, segundo a qual o progresso necessita ser avaliado verificando-se se houve aumento da liberdade das pessoas; e a razão da eficácia, na qual o desenvolvimento depende da livre-condição de agente das pessoas. Há nessa análise uma ligação entre a liberdade individual e a realização do desenvolvimento pessoal, que vai além da mera relação constitutiva, pois isso significa que:

(...) o que as pessoas conseguem positivamente realizar é influenciado por oportunidades econômicas, liberdades políticas, poderes sociais e por condições habilitadoras como boa saúde, educação básica e incentivo e aperfeiçoamento de iniciativas. As disposições institucionais que proporcionam essas oportunidades são influenciadas pelo exercício das liberdades das pessoas, mediante a liberdade para participar da escolha social e da tomada de decisões públicas que impelem o progresso dessas oportunidades (SEN, 2000, p. 19).

Além de afirmar a importância avaliatória da liberdade, Amartya Sen (2000) registra a existência de uma relação empírica que vincula os diversos tipos de liberdades existentes. Embora reconheça a importância dos vários tipos de liberdades no processo de desenvolvimento, o autor destaca cinco que considera fundamentais: a) liberdades políticas; b) facilidades econômicas; c) oportunidades sociais; d) garantia de transparência, e e) segurança protetora.

A abstração de liberdade adotada pelo autor envolve tanto os processos que permitem a liberdade de ações e decisões quanto as oportunidades reais de que dispõem, dadas as circunstâncias pessoais e sociais em que vivem. Dessa forma, cada um desses tipos de direitos

Rev. de Direito, Economia e Desenvolvimento Sustentável | e-ISSN: 2526-0057| Goiânia| v. 5 | n. 1 | p. 39-56| 
e oportunidades elencados como fundamentais contribui com a promoção da capacidade geral de uma pessoa.

\section{CONCLUSÃO}

A elaboração deste artigo teve por base em fornecer argumento para se entender que as políticas públicas desenvolvidas pelo Estado têm grande peso na saúde e no crescimento das empresas. As decisões dos políticos podem promover desenvolvimento ou atraso, riqueza ou miséria.

O conceito de desenvolvimento é muito mais abrangente que o conceito de crescimento econômico. Enquanto este demonstra uma variação na taxa de crescimento do PIB, o primeiro representa a melhoria das condições socioeconômicas dos indivíduos.

Por longo tempo, a noção de desenvolvimento como sinônimo de crescimento econômico, progresso, industrialização e uso intensivo de tecnologia, foi concebida como o único caminho para a garantia da qualidade de vida e de um desejável e ilimitado aperfeiçoamento da humanidade.

A compreensão de desenvolvimento como crescimento econômico começou a dar sinais de esgotamento a partir dos anos 60, após a falência de grande parte dos projetos desenvolvimentistas nacionais, pontuando-se a necessidade de repensar o sentido atribuído ao desenvolvimento para torná-lo um termo qualitativo, ou seja, relacionado à qualidade de vida da sociedade.

A partir dos anos 80, fortaleceu-se o senso de solidariedade e as preocupações ambientais. Disso, cresceu a proposta de sustentabilidade, atrelando ao desenvolvimento uma concepção pluridimensional, envolvendo a perspectiva ambiental ao lado da econômica, da política, da social e da cultural.

A importância do desenvolvimento, solidificando-se como um processo público de superação de problemas sociais avaliado a partir da sua capacidade de eliminar as diversas privações vivenciadas pelos indivíduos na sociedade, passando a ser defendida esta concepção, pela Organização das Nações Unidas, formalmente a partir de 1986 e, desde então, defendida por entidades e instituições nacionais e internacionais, constituindo-se na base teórica que orienta um conjunto de políticas públicas atualmente em execução.

Conclui-se que essas mudanças que ocorrem com relação à concepção de desenvolvimento ao longo da modernidade, em especial a concepção de desenvolvimento como liberdade, se coadunam com a percepção de desenvolvimento, defendida na atualidade pela Organização das Nações Unidas como um processo social e pluridimensional, sendo que o estado possui parcela extremamente importante para o crescimento das empresas e da sociedade.

\section{REFERÊNCIAS}

ANDRADE, Paulo Roberto Siqueira. Economia Política na Universidade: Aspectos Jurídicos. Rio de Janeiro: América Jurídica, 2005.

ARANHA, Maria Lúcia de Arruda; MARTINS, Maria Helena Pires. Filosofando: Introdução à Filosofia. $2^{\text {a }}$ ed. rev. atual. São Paulo: Moderna, 1993.

BARROCO, Maria Lucia Silva. Ética e Serviço Social: fundamentos ontológicos. $2^{\text {a }}$. ed. São Paulo: Cortez, 2001.

BERCOVICI, Gilberto. Constituição econômica e desenvolvimento: uma leitura a partir da 
Constituição de 1988. São Paulo: Malheiros, 2005.

BRESSER PEREIRA, Luiz Carlos. O conceito histórico de desenvolvimento econômico. São Paulo: EESP/FGV, Texto para discussão n.157, 2006. Disponível em: http://www.bresserpereira.org.br/papers/2008/08.18.ConceitoHist\%C3\%B3ricoDesenvolvime nto.31.5.pdf. Acesso em 10, out de 2018.

Crise e Recuperação da Confiança. 2009. Disponível em http://www.bresserpereira.org.br/articles/2013/19-CriseeRecupera\%C3\%A7\%C3\%A3oda-Confian\%C3\%A7a.pd. Acesso em 15, out. 2018.

CAMPOS, G. M. M. Desenvolvimento e sindicalismo: o projeto de economia solidária da Central Única dos Trabalhadores no Pajeú Pernambuco - a experiência da Ecosol Pajeú/PE. 2009. Dissertação (Mestrado em Ciências Sociais) - Universidade Federal do Rio Grande do Norte, 2009.

CASTRO, M. C. de. Desenvolvimento sustentável. Revista Economia e Empresa, Instituto Presbiteriano Mackenzie, v. 3, n.3, jul./set. 1996.

CLARK, Giovani. O Município em Face do Direito Econômico. Belo Horizonte: Del Rey, 2001.

DERANI, Cristiane. Direito ambiental econômico. 3. ed. São Paulo: Max Limonad, 2008.

DIEGUES, A. Desenvolvimento sustentável ou sociedades sustentáveis: da crítica dos modelos aos novos paradigmas. In: São Paulo em Perspectiva, 1992, vol. 6, 1 e 2. jan/jun. 1992.

FAUVRELLE, Thiago; Targino, Ivan. $O$ desempenho da econômica paraibana no contexto nacional: a década de 2000. João Pessoa: UFPB, Cadernos do Logepa, v. 6, n. 1, p. 76-98, jan/jun. 2011.

FONTANA, Dino F. História da Filosofia, Psicologia e Lógica. 3 ed. São Paulo: Saraiva, 1969. FURTADO, Celso. Pequena introdução ao desenvolvimento: enfoque interdisciplinar. São Paulo: Ed. Nacional, 1981.

GODOY, Sara Gurfinkel Marques de; PAMPLONA, João Batista. O Protocolo de Kyoto e os países em desenvolvimento. In: Pesquisa \& Debate, SP, v. 18, n. 2 (32), p. 329-353, 2007.

HERCULANO, S. C. Do desenvolvimento (in) suportável à sociedade feliz. In: GOLDENBERG, M. (Coord.). Ecologia, ciência e política. Rio de Janeiro: Revan, 1992.

LAYRARGUES, P. P. Do ecodesenvolvimento ao desenvolvimento sustentável: evolução de um conceito? In: Proposta, Rio de Janeiro: Fase, n. 71, p. 5-10, 1997.

MANKIW, N. Gregory. Introdução à Economia: Princípios de Micro e Macroeconomia. Trad. Maria José Cyhlar Monteiro. Rio de Janeiro: Campus, 1999.

MARX, Karl. Prefácio à crítica da economia política de 1859. Disponível em: http://www.insrolux.org/textosmarxistas/economiapolitica.htm. Acesso em 10 out de 2018.

Nova Cultural, 1996. Para a Crítica da Economia Política. Trad. Edgard Malagodi. São Paulo: O Capital. São Paulo: Nova Cultural, 1996.

MYRDAL, Gunnar. Teoria Econômica e Regiões Subdesenvolvidas. Ed. Paz e Terra. Rio de Janeiro, 1974.

Rev. de Direito, Economia e Desenvolvimento Sustentável | e-ISSN: 2526-0057| Goiânia| v. 5 | n. 1 | p. 39-56| 
NOBRE, M. Desenvolvimento sustentável: origens e significado atual. In: AMAZONAS, M. de C.; NOBRE, M. Desenvolvimento sustentável: a institucionalização de um conceito. Brasília: Edições Ibama, 2002.

ORGANIZAÇÃO DAS NAÇÕES UNIDAS (ONU). Comissão Mundial sobre o Meio Ambiente e Desenvolvimento. Relatório Brundtland. 1987.

PASSOS, Carlos Roberto Martins e NOGAMI, Otto. Princípios de Economia. $5^{\text {a }}$ ed. rev. São Paulo: Pioneira Thompson Learning, 2005.

PORSSE, Melody de Campos et al. A abordagem das capacitações: um modelo alternativo para as ações públicas. In: Redes, Santa Cruz do Sul, v. 13, n. 1, p. 159-181, jan./abr. 2008.

SACHS, Ignacy. Desenvolvimento includente, sustentável, sustentado. Rio de Janeiro: Garamond, 2001.

. A terceira margem: em busca do ecodesenvolvimento. Tradução Rosa Freire d'Aguiar. São Paulo: Companhia das Letras, 2009.

SEN, Amartya. Desenvolvimento como liberdade. São Paulo: Ed. Companhia das Letras, 2000. SILVA, Dalvanir Avelino; NELSON, Aline V. Medeiros; RAMOS SILVA, Maria Aparecida. Do Desenvolvimento Como Crescimento Econômico ao Desenvolvimento Como Liberdade. A Evolução de um Conceito. Artigo Desenvolvimento em Questão. Editora Unijuí. Ano 16, nº 42. Jan/Mar 2018.

Disponível

em https://revistas.unijui.edu.br/index.php/desenvolvimentoemquestao/article/view/5827. Acesso em 20, out. 2018.

SIMONSEN, Mário H. e CAMPOS, Roberto de O. A Nova Economia Brasileira. Rio de Janeiro: Editora Biblioteca do Exército, 1975.

SMITH, Adam. A riqueza das nações: investigação sobre sua natureza e suas causas. Vol. I. São Paulo: Editora Nova Cultural, 1996.

SOUZA, Nali de J. Desenvolvimento Econômico. São Paulo: Atlas, 1993.

TAVARES, André Ramos. Direito Constitucional Econômico. 2. Edição. São Paulo: Método, 2006.

VALLE, C. E. Qualidade ambiental. ISO 14000. 4ª ed. ampl. São Paulo: Ed. Senac, 2002.

VIEIRA, Edson Trajano; SANTOS, Moacir José dos. Desenvolvimento Econômico RegionalUma revisão histórica e teórica. In: Revista Brasileira de Gestão e Desenvolvimento Regional. v. 8, n. 2, 2012.

VILANOVA, Lourival. Escritos jurídicos e filosóficos. São Paulo: IBET, 2003. 